\title{
Potássio via recobrimento de sementes de soja: efeitos na qualidade fisiológica e no rendimento
}

\author{
Potassium via coating of soybean seeds: effects on physiological quality and yield
}

\author{
Lizandro Ciciliano Tavares ${ }^{{ }^{*}}$ Lilian Madruga de Tunes ${ }^{\mathrm{I}}$ André Pich Brunes ${ }^{\mathrm{I}}$ \\ Daniel Ândrei Robe Fonseca ${ }^{I}$ Cassyo de Araújo Rufino ${ }^{I}$ \\ Antonio Carlos Souza Albuquerque Barros ${ }^{\mathrm{I}}$
}

RESUMO

No presente trabalho, o objetivo foi avaliar a qualidade fisiológica e o rendimento de sementes de soja recobertas com diferentes fontes e concentrações de potássio. Utilizando a cultivar de soja 'CD 201', cujo delineamento experimental adotado foi inteiramente casualizado e os tratamentos constaram de um fatorial $2 \times 5$ (fontes de potássio: $\mathrm{KCl}$ e $\mathrm{K}_{2} \mathrm{SO}_{4}$ e níveis: 0, 5 , 50 , 500 e $5000 \mathrm{mg} \mathrm{L}^{-1}$ ), totalizando dez tratamentos. As sementes foram recobertas com $2 m L$ de solução de potássio $+2 m L$ de Polímero (Sepiret $\left.{ }^{\circledR}\right)+2 m L$ de Inoculante (Rizofix ${ }^{\circledR}$ ) por quilo, totalizando $6 \mathrm{~mL} \mathrm{~kg}^{-1}$ de semente. As variáveis analisadas foram primeira contagem da germinação, germinação, envelhecimento acelerado, teste de frio e comprimento da parte aérea e raiz; após a colheita, avaliou-se a qualidade fisiológica e o rendimento das sementes produzidas. O recobrimento de sementes de soja, cultivar 'CD 201', com cloreto e sulfato de potássio não influencia na germinação, mas o cloreto de potássio beneficia o desempenho das plântulas. O potássio via recobrimento de sementes com sulfato e cloreto de potássio até $5000 \mathrm{mg}^{-1}$ de semente não interfere no seu rendimento, porém o sulfato de potássio produz sementes de melhor qualidade.

Palavras-chave: Glycine $\max ($ L.) Merrill, tratamento, nutrientes, vigor, germinação.

\section{ABSTRACT}

This study aimed to evaluate the physiological quality and yield of soybean seeds coated with different sources and concentrations of potassium. Using soybean cultivar ' $C D$ 201'. The experimental design was completely randomized and the treatments were a factorial $2 \times 5$ (sources of potassium: $\mathrm{KCl}$ and $\mathrm{K}_{2} \mathrm{SO}_{4}$ and levels: 0, 5, 50, 500 and $5000 \mathrm{mg} \mathrm{L}^{-1}$ ), a total of ten treatments, with four replications. The seeds were covered with 2 $\mathrm{ml}$ of solution of potassium $2 m L+$ Polymer $\left(\right.$ Sepire $\left.^{\circledR}\right)+2 m L$ of inoculants (Rizofix ${ }^{\circledR}$ ) per $\mathrm{kg}$ of seed, totaling $6 \mathrm{~mL} \mathrm{~kg}^{-1}$ seeds. The variables analyzed after treatment of the seeds were first count of germination, germination, accelerated aging, cold test and length of shoot and root. After harvest, we evaluated the physiological seed quality and seed yield. It is concluded that the coating of soybean seeds, cultivar 'CD 201', chloride and potassium sulfate does not influence the germination of treated seed, however potassium positively influences the performance of seedlings. The seed coating by potassium sulphate and potassium chloride to $5000 \mathrm{mg} \mathrm{L}^{-1}$ seed do not interfere with seed yield, but the potassium sulphate seed produces higher quality than chloride.

Key words: Glycine $\max (L$.$) Merrill, treatment, nutrients, vigor,$ germination.

\section{INTRODUÇÃO}

O potássio, presente nas plantas, como o cátion $\mathrm{K}^{+}$, desempenha importante função na regulação do potencial osmótico das células vegetais, ativando muitas enzimas envolvidas na respiração e fotossíntese (TAIZ \& ZEIGER, 2004). Na cultura da soja, depois do nitrogênio, o potássio é o segundo elemento mais absorvido pelas plantas, sendo que, em cada $1.000 \mathrm{~kg}$ de sementes produzidas, são extraídos $20 \mathrm{~kg}$ de $\mathrm{K}_{2} \mathrm{O}$ do solo. O potássio auxilia a formação dos nódulos, aumenta o teor de óleo nas sementes, beneficiando sua germinação e vigor (MASCARENHAS et al., 1988). O primeiro sintoma visível da deficiência de potássio é a clorose com manchas, que evolui para necrose, principalmente nos ápices foliares, nas margens e entre nervuras, cujas lesões necróticas estendem-se em direção a base da folha (TAIZ \& ZEIGER, 2004).

\footnotetext{
IDepartamento de Fitotecnia, Universidade Federal de Pelotas (UFPel), 96001-970, Pelotas, RS, Brasil. E-mail: lizandro_cicilianotavares@yahoo.com.br.
} *Autor para correspondência. 
Como os fertilizantes em sua grande maioria são sais, sua aplicação pode prejudicar a germinação das sementes e o desenvolvimento inicial das plântulas, caso sejam colocados no solo próximo a elas. O efeito da salinidade na germinação ocorrerá quando a concentração de sais da solução for maior que a da semente (DESAI et al., 2004) e a influência negativa da adição de sais, como o cloreto de potássio, depende do incremento provocado pelo fertilizante na concentração eletrolítica da solução do solo nas regiões próximas das sementes no momento da germinação. Esse incremento depende da dose do fertilizante e do poder tampão de potássio do solo e este, por sua vez, varia com a textura, composição mineralógica, $\mathrm{pH}$, teores de matéria orgânica e de água no solo.

A alta concentração de sais dificulta a absorção de água pelas sementes e radicelas, devido ao aumento da pressão osmótica externa às células (MARSCHNER, 1995). Sendo assim, além dos prejuízos na germinação, o excesso de sais pode comprometer o desenvolvimento radicular e vegetativo das plantas (SOUZA et al., 2007), sendo mais evidentes, principalmente, em adubações mal realizadas do ponto de vista da localização dos adubos e também de quantidades acima da recomendação.

O potássio não faz parte de compostos orgânicos nem desempenha função estrutural na planta, mas atua na ativação de aproximadamente 50 enzimas, destacando-se as sintetases, oxiredutases, desidrogenases, transferases, quinases, aldolases e a rubisco, enzima chave no processo fotossintético. Ele também está envolvido na síntese de proteínas, de forma que, em plantas com baixos teores de potássio, há redução nessa síntese, com acúmulo de compostos de baixa massa molecular, como aminoácidos, amidas, aminas e nitratos (MARSCHNER, 1995; MALAVOLTA et al., 1997).

Cultivando soja em solos com alta deficiência de potássio, MASCARENHAS et al. (1988) observaram como sintoma de deficiência o amarelecimento dos bordos foliares. Após o florescimento, ocorreu baixo índice de flores fecundadas, grande proporção de vagens vazias e retorcidas, além da presença de sementes chochas nas vagens normais.

O conteúdo de potássio nas sementes pode ser importante na fase inicial de crescimento das plantas, quando o sistema radicular está pouco desenvolvido para o suprimento adequado da planta com esse nutriente, uma vez que ele é essencial devido as várias funções dentro da planta, a exemplo do controle osmótico e regulação da atividade enzimática da via glicolítica (MALAVOLTA, 2006; EPSTEIN \& BLOOM, 2006).

Aliado à baixa disponibilidade desse nutriente, existe a possibilidade de perdas por lixiviação, quando aplicado direto no solo, principalmente em solos com textura mais arenosa, reforçando a importância de se estudar alternativas de formas e fontes de aplicação para a diminuição de perdas e ocorrência de problemas com a adubação de potássio. Em virtude do que foi exposto, a técnica de recobrimento de sementes é uma alternativa de aplicação de baixas doses e/ou concentrações de potássio via sementes, assumindo como uma adubação altamente localizada com doses mais precisas.

Diante desse contexto, no presente trabalho, o objetivo foi avaliar a qualidade fisiológica e o rendimento de sementes de soja recobertas com diferentes fontes e concentrações de potássio.

\section{MATERIAL E MÉTODOS}

O trabalho foi conduzido no Laboratório Didático de Análise de Sementes (LDAS) e em casa de vegetação, da Faculdade de Agronomia "Eliseu Maciel” da Universidade Federal de Pelotas, sendo utilizadas sementes de soja da cultivar 'CD 201'. Os tratamentos constaram de duas fontes de potássio ( $\mathrm{KCl}$ e $\mathrm{K}_{2} \mathrm{SO}_{4}$ ) e cinco níveis $(0,5,50,500$ e 5000mg $\mathrm{L}^{-1}$ de produto), totalizando dez tratamentos, com quatro repetições. As sementes foram recobertas com $2 \mathrm{~mL}$ de solução de potássio $+2 \mathrm{~mL}$ de polímero $\left(\right.$ Sepiret $\left.^{\circledR}\right)+2 \mathrm{~mL}$ de Inoculante $\left(\right.$ Rizofix $\left.^{\circledR}\right)$ por quilo de semente, totalizando $6 \mathrm{~mL} \mathrm{~kg}^{-1}$.

As sementes foram tratadas na seguinte ordem de aplicação: nutriente + polímero + inoculante, sendo esses produtos colocados no fundo de um saco plástico e distribuídos até uma altura de aproximadamente $15 \mathrm{~cm}$ deste. A seguir, adicionouse $0,2 \mathrm{~kg}$ de sementes no interior do saco plástico, agitando por três minutos e, na sequência, as sementes foram colocadas para secar à temperatura ambiente durante 24 horas (NUNES, 2005).

A qualidade fisiológica das sementes tratadas foi avaliada pelos testes de: germinação (G): realizado com quatro subamostras de 50 sementes para cada tratamento, cuja semeadura foi em substrato papel do tipo germitest, previamente umedecido em água destilada na proporção de 2,5 vezes a sua massa seca, e os rolos foram mantidos em germinador à temperatura de $25^{\circ} \mathrm{C}$. As avaliações foram efetuadas no oitavo dia após a semeadura, conforme as Regras para Análise de Sementes (BRASIL, 2009) e os resultados expressos em porcentagem de plântulas 
normais. Primeira contagem da germinação (PCG): avaliada aos cinco dias após a semeadura por ocasião da realização do teste de germinação. Envelhecimento acelerado (EA): realizado em caixa tipo gerbox $(11 \times 11 \times 3,5 \mathrm{~cm})$ com tela metálica em que foram adicionados $40 \mathrm{~mL}$ de água destilada ao fundo de cada uma e sobre a tela foram distribuídas uniformemente em uma única camada as sementes de cada tratamento. Em seguida, as caixas contendo as sementes foram tampadas e acondicionadas em incubadora do tipo Biochemical Oxigen Demand (B.O.D.), a $41^{\circ} \mathrm{C}$ por 48 horas; após esse período, as sementes foram submetidas ao teste de germinação com avaliação no quinto dia. Teste de frio (TF): conduzido com quatro subamostras de 50 sementes para cada unidade experimental, sendo os rolos de papel colocados em sacos plásticos, os quais foram vedados e mantidos em câmara regulada à temperatura de $10^{\circ} \mathrm{C}$ durante sete dias. Após esse período, foram transferidas para um germinador e mantidas nas mesmas condições do teste de germinação, sendo avaliadas após cinco dias (CÍCERO \& VIEIRA, 1994). Comprimento de parte aérea e raiz: a avaliação foi realizada em quatro subamostras de 20 sementes para cada tratamento, as quais foram distribuídas em substrato rolo de papel do tipo germitest, em duas linhas retas longitudinais e desencontradas no seu terço superior. Após a confecção, os rolos foram embalados em sacos plásticos e colocados em germinador regulado à temperatura constante de $25^{\circ} \mathrm{C}$ (NAKAGAWA, 1999); no quinto dia após a semeadura, foi avaliado o comprimento da parte aérea e raiz das plântulas normais, sendo cada plântula medida separadamente e, em seguida, foi calculado o comprimento médio das partes.

Com as mesmas sementes tratadas com potássio, polímero e inoculante, realizouse a semeadura em casa de vegetação, sendo oito sementes por vaso com capacidade de 15 litros, permanecendo três plantas por vaso, preenchidos com solo peneirado, coletado do horizonte A1 de um Planossolo Háplico eutrófico solódico (STRECK et al., 2008), pertencente à unidade de mapeamento Pelotas. A adubação foi realizada de acordo com os resultados da análise de solo e recomendações da Comissão de Química e Fertilidade do Solo - RS/ SC (2004). Os fertilizantes utilizados foram apenas nitrogênio, fósforo e potássio, com aplicação 14 dias antes da semeadura, e a calagem ocorreu trinta dias antes desta; em seguida, as unidades experimentais foram irrigadas diariamente, mantendo-se o solo próximo à capacidade de campo.
A colheita das sementes ocorreu quando as plantas estavam no estádio R8, no qual se encontram em maturação plena, com 95\% das vagens com coloração de madura. O rendimento de sementes por planta foi determinado pela pesagem do número de sementes resultantes, ajustando-se o peso ao teor de água de $13 \%$ de umidade, e o número de sementes por planta foi determinado por contagem manual. Em seguida, realizou-se a avaliação da qualidade fisiológica das sementes produzidas pelos testes de primeira contagem da germinação, germinação e envelhecimento acelerado, descritos anteriormente.

O delineamento experimental das etapas de laboratório e casa de vegetação foi inteiramente casualizado, em quatro repetições, cujos dados foram submetidos à análise de variância, sendo os efeitos qualitativos analisados pelo teste de Tukey a $5 \%$ de probabilidade, tanto para os fatores isolados quanto para a interação entre eles, enquanto os dados quantitativos foram submetidos à regressão polinomial; para a análise estatística, foi utilizado o Sistema de Análise Estatística Winstat versão 2.0 (MACHADO \& CONCEIÇÃO, 2003).

\section{RESULTADOS E DISCUSSÃO}

Pelos dados da tabela 1, verifica-se que não houve interação entre as concentrações e fontes de potássio, sendo então comparadas as médias das fontes, constatando-se que, independente da fonte e concentração utilizada de sulfato e cloreto de potássio via recobrimento de sementes de soja, as variáveis primeira contagem da germinação, germinação, envelhecimento acelerado e teste de frio não diferiram significativamente, porém verificou-se que a fonte $\mathrm{K}_{2} \mathrm{SO}_{4}$ proporcionou desempenho inferior ao da fonte $\mathrm{KCl}$, tanto no comprimento de parte aérea como de raiz.

Apesar da presente pesquisa ter sido realizada com adubação potássica via sementes, os dados obtidos concordam com BORBA et al. (1981), que semelhantemente não verificaram efeito da adubação potássica sobre a germinação e vigor de sementes de três cultivares de soja. Da mesma maneira, VIEIRA et al. (1987) também não observaram efeitos adversos do uso de diferentes doses de potássio sobre a germinação de sementes de soja, o que pode ser explicado em razão das doses utilizadas atenderam às recomendações técnicas para a cultura em questão. Além disso, infere-se que o posicionamento do adubo via sementes pode ter facilitado a sua absorção, favorecendo a nutrição e facilitando, dessa forma, a velocidade de crescimento das plântulas. No entanto, em outras espécies, a 
Tabela 1 - Primeira contagem da germinação (PCG), germinação (G), envelhecimento acelerado (EA), teste de frio (TF), comprimento de parte aérea (CPA) e raiz (CR) de plântulas de soja em função do recobrimento de sementes com diferentes fontes e concentrações de potássio.

\begin{tabular}{|c|c|c|c|c|c|c|c|c|c|c|c|c|}
\hline $\begin{array}{l}\text { Concentrações } \\
\left(\mathrm{mg} \mathrm{L}^{-1}\right)\end{array}$ & $\begin{array}{l}\mathrm{K}_{2} \mathrm{SO}_{4} \\
-----\mathrm{PC}\end{array}$ & $\mathrm{KCl}$ & $\mathrm{K}_{2} \mathrm{SO}_{4}$ & ------ & $\mathrm{K}_{2} \mathrm{SO}_{4}$ & ------- & $\mathrm{K}_{2} \mathrm{SO}_{4}$ & ----- & $\mathrm{K}_{2} \mathrm{SO}_{4}$ & A------- & $\mathrm{K}_{2} \mathrm{SO}_{4}$ & 2-------- \\
\hline 0 & 82 & 82 & 89 & 88 & 83 & 82 & 80 & 81 & 10,5 & 10,4 & 10,0 & 9,9 \\
\hline 5 & 83 & 83 & 90 & 89 & 82 & 82 & 81 & 81 & 12,2 & 12,5 & 10,4 & 10,1 \\
\hline 50 & 83 & 83 & 91 & 90 & 82 & 82 & 81 & 81 & 11,5 & 12,8 & 10,4 & 11,8 \\
\hline 500 & 84 & 83 & 91 & 91 & 84 & 82 & 83 & 82 & 11,5 & 12,3 & 10,7 & 11,9 \\
\hline 5000 & 84 & 84 & 91 & 91 & 85 & 84 & 83 & 81 & 11,4 & 11,7 & 11,6 & 10,9 \\
\hline Média & $83 \mathrm{~A} *$ & $83 \mathrm{~A}$ & $90 \mathrm{~A}$ & $90 \mathrm{~A}$ & $84 \mathrm{~A}$ & $83 \mathrm{~A}$ & $83 \mathrm{~A}$ & $84 \mathrm{~A}$ & $11,4 \mathrm{~B}$ & $11,9 \mathrm{~A}$ & 10,6 B & 10,9 A \\
\hline CV (\%) & 3, & & & & & & & & 5 & & & 7,8 \\
\hline
\end{tabular}

*Médias seguidas pela mesma letra maiúscula na linha, em cada variável resposta, não diferem estatisticamente entre si, pelo teste de Tukey a $5 \%$ de probabilidade.

adubação potássica realizada via solo não afetou a qualidade das sementes logo após a colheita, como pode ser observado em trabalhos de ROSSETTO et al. (1997) com canola.

Pela observação das figuras 1A e B, foi possível verificar efeito significativo das concentrações e da média das fontes $\mathrm{KCl}$ e $\mathrm{K}_{2} \mathrm{SO}_{4}$ no comprimento de parte aérea e raiz, obtendo-se respostas diferentes, sendo que, na média de ambas as fontes até $5000 \mathrm{mg} \mathrm{kg}^{-1}$ de semente, os dados de comprimento da parte aérea se ajustaram ao modelo quadrático, ou seja, houve uma resposta mais lenta do crescimento, porém a concentração de $50 \mathrm{mg} \mathrm{kg}^{-1}$ de semente foi a melhor, enquanto, no comprimento de raiz, houve resposta linear, observando-se que, com o aumento da concentração, houve incremento dessa variável (Figura 1A), podendo-se inferir que a aplicação de potássio via recobrimento de sementes provavelmente influenciou no crescimento inicial das raízes da soja até a concentração de 5000mg $\mathrm{kg}^{-1}$, pelo fato de as primeiras raízes das sementes enriquecidas com potássio estarem em contato direto com o nutriente.

Pelos dados da figura $1 \mathrm{~B}$, verificase comportamento quadrático para o número de sementes por planta com o aumento da concentração até $5000 \mathrm{mg} \mathrm{kg}^{-1}$ de semente, mas infere-se que, nas doses mais altas, a tendência foi de redução no número de sementes por planta e comprimento da parte aérea das plântulas, o que pode ser relacionado à toxidez causada pela alta concentração dos sais de $\mathrm{K}_{2} \mathrm{SO}_{4}$ e $\mathrm{KCl}$ em contato com as sementes. Resultados semelhantes foram constatados por MATEUS et al.
(2007), cujas sementes de Brachiaria brizantha tiveram sua germinação reduzida, quando em contato com o sal de $\mathrm{KCl}$. O efeito salino na germinação ocorre quando a concentração de sais da solução for maior que a da semente (DESAI et al., 2004); logo, em baixas concentrações, não foram verificados os efeitos adversos da salinidade nas sementes.

Os dados da tabela 2 indicam que não ocorreu interação significativa entre concentrações e fontes, sendo então comparadas as médias das fontes, mas não se constatou efeito significativo na primeira contagem de germinação e envelhecimento acelerado de sementes de soja recobertas com $\mathrm{K}_{2} \mathrm{SO}_{4}$ e $\mathrm{KCl}$, porém verificou-se que a germinação das sementes produzidas foi afetada positivamente. Assim, observa-se efeito significativo na germinação das sementes de soja produzidas, provenientes do recobrimento com $\mathrm{K}_{2} \mathrm{SO}_{4}$, enquanto NAKAGAWA et al. (1983) não obtiveram efeito do fósforo sobre a qualidade de sementes de soja.

A disponibilidade de macronutrientes como o nitrogênio, fósforo e potássio influem na boa formação do embrião, do órgão de reserva e do tecido protetor, assim como na sua composição química e, consequentemente, na qualidade fisiológica (CARVALHO \& NAKAGAWA, 2000). O número de sementes por planta e o rendimento destas não sofreram influência do recobrimento das sementes de soja com potássio. Em estudo com recobrimento em sementes de soja, conduzido por PESKE et al. (2009), quando foi realizado com fósforo, propiciou à indústria de sementes um aumento de produtividade em torno de $14 \%$. 


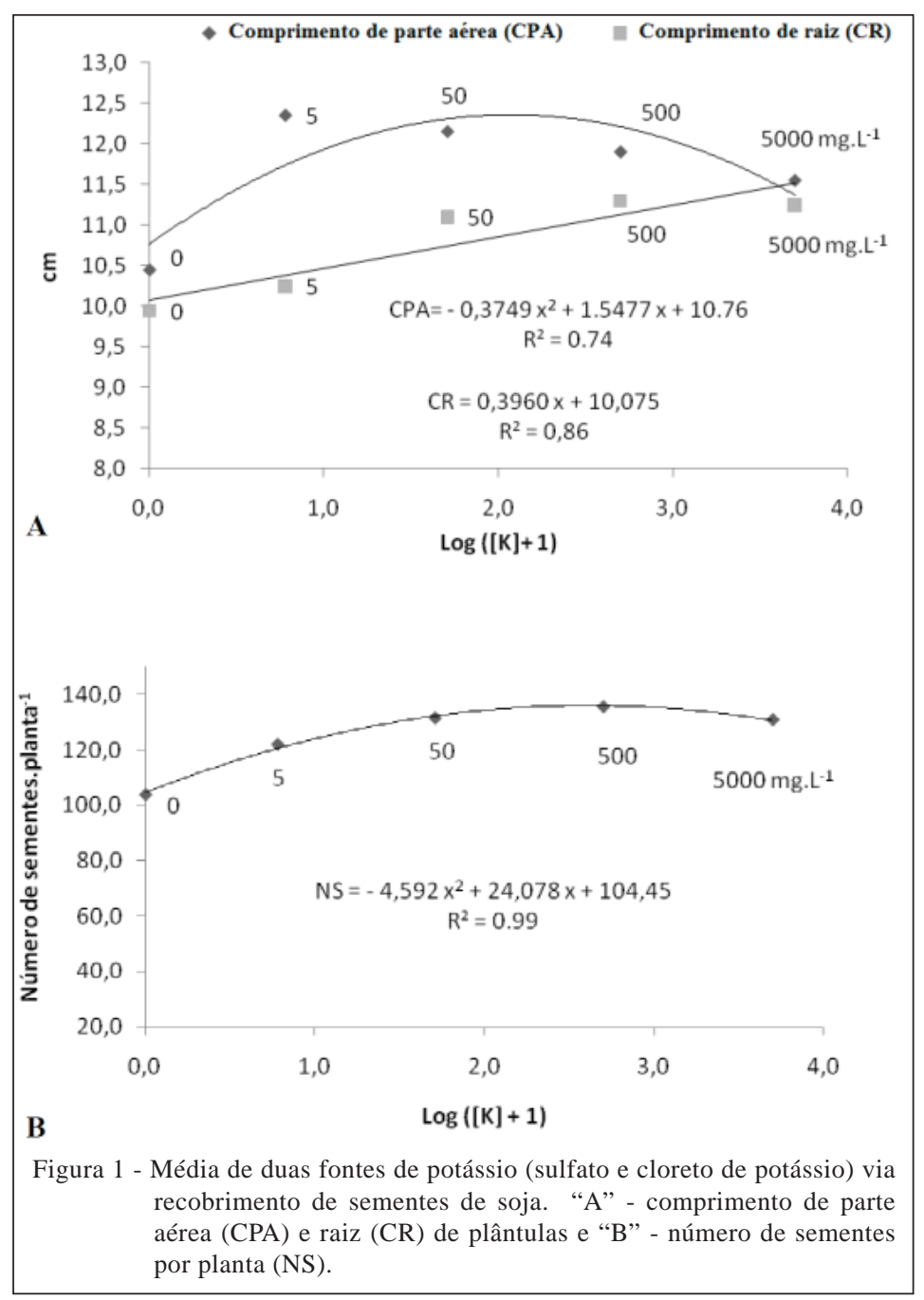

Uma boa formação do embrião e tecidos de reserva, assim como sua composição química, dependem de uma adequada disponibilidade de nutrientes no substrato de crescimento das plantas, o que certamente irá influenciar positivamente no metabolismo e vigor da semente (CARVALHO \& NAKAGAWA, 2000), resultando numa planta bem nutrida desde a fase inicial de crescimento, para consequentemente produzir maior número de sementes por planta.

$\mathrm{Na}$ maioria dos trabalhos de pesquisa, não tem ocorrido resposta à adubação potássica, fato justificado pelos teores do nutriente se encontrarem em níveis médios ou altos no solo, porém deve-se ressaltar a importância do potássio, visto ser considerado indispensável para obtenção de altas produtividades na cultura da soja, não apenas pela manutenção de melhores condições para o crescimento da planta, mas principalmente para a fixação biológica do nitrogênio (BORKERT \& YAMADA, 2000), além de contribuir para a maior resistência das plantas ao ataque de doenças (MASCARENHAS et al., 2000).

Esse nutriente possui grande destaque na cultura da soja, pois ajuda na formação de nódulos, reduz a deiscência das vagens, aumenta o teor de óleo nas sementes e também beneficia sua germinação, vigor e qualidade das sementes, respectivamente, além de aumentar a resistência ao fungo Diaporthe phaseolorum sojae, causador do cancro da haste (MASCARENHAS et al., 1988).

\section{CONCLUSÃO}

O recobrimento de sementes de soja, cultivar 'CD 201', com cloreto e sulfato de potássio não influencia na germinação das sementes, mas o cloreto de potássio beneficia o desempenho das plântulas. O potássio via recobrimento de sementes 
Tabela 2 - Primeira contagem da germinação (PCG), germinação (G), envelhecimento acelerado (EA), número de sementes por planta (NS) e rendimento de sementes (R) de soja provenientes de sementes recobertas com diferentes fontes e concentrações de potássio.

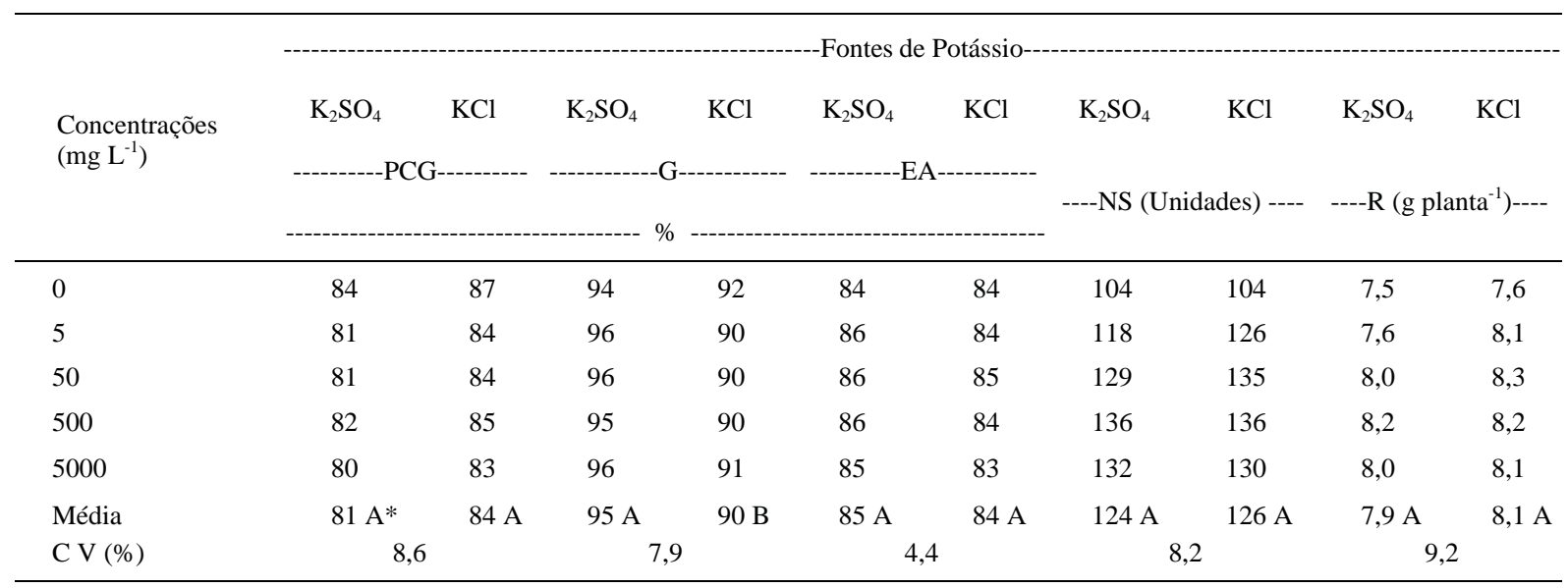

*Médias seguidas pela mesma letra maiúscula na linha, em cada variável resposta, não diferem estatisticamente entre si, pelo teste de Tukey a $5 \%$ de probabilidade.

com sulfato e cloreto de potássio até 5000mg L-1 de semente não interfere no rendimento delas, porém, com o sulfato de potássio, produzem-se sementes de melhor qualidade.

\section{REFERÊNCIAS}

BORBA, C.S. et al. Efeito da adubação e da umidade do solo sobre a qualidade da semente de soja (Glycine $\max$ (L.) Merrill). Agronomia Sulriograndense, v.17, n.1, p.51-68, 1981.

BORKERT, C.M.; YAMADA, T. Soybean responses to potassium fertilization in a low fertility Oxisol. Better Crops International, v.14, n.2, p.16-17, 2000.

BRASIL. Ministério da Agricultura, Pecuária e Abastecimento. Regras para análise de sementes. Brasília: Secretaria de Defesa Agropecuária, MAPA/ACS, 2009. 395p.

CARVALHO, N.M.; NAKAGAWA, J. Sementes: ciência, tecnologia e produção. Jaboticabal: FUNEP. 2000. 588p.

CÍCERO, S.M.; VIEIRA, R.D. Teste de frio. In: VIEIRA, R.D.; CARVALHO, N.M. Testes de vigor em sementes. Jaboticabal: FUNEP, 1994. p.151-164.

COMISSÃO DE QUÍMICA E FERTILIDADE DO SOLO - RS/ SC. Manual de adubação e calagem para os Estados do Rio Grande do Sul e de Santa Catarina. 10.ed. Porto Alegre, SBCS Núcleo Regional Sul/UFRGS, 2004. 400p.

DESAI, B.B. et al. Seeds handbook: biology, production, processing and storage. 2.ed. New York, Marcel Dekker, 2004. 787p.

EPSTEIN, E.; BLOOM, A.J. Nutrição mineral de plantas: princípios e perspectivas. Londrina: Planta, 2006. 410p.

MACHADO, A.A.; CONCEIÇÃO, A.R. Sistema de análise estatística para Windows. Winstat. Pelotas: UFPel, 2003. Versão 2.0.
MALAVOLTA, E. et al. Avaliação do estado nutricional das plantas: princípios e aplicações. 2.ed. Piracicaba: POTAFOS, 1997. 319p.

MALAVOLTA, E. Manual de nutrição de plantas. São Paulo: Agronômica Ceres, 2006. 631p.

MASCARENHAS, H.A.A. et al. Zinco nas folhas de soja em função da calagem. Bragantia, v.47, n.1, p.137-142, 1988.

MASCARENHAS, H.A.A. et al. Calcário e potássio para a cultura de soja. Scientia Agricola, v.57, n.3, p.445-449, 2000.

MARSCHNER, H. Mineral nutrition of higher plants. 2.ed. London: Academic, 1995. 889p.

MATEUS, G.P. et al. Fontes e períodos de contato de fertilizantes e germinação de sementes de Brachiaria brizantha. Revista Brasileira de Ciência do Solo, v.31, n.1, p.177-183, 2007. Disponível em: <http://www.scielo.br/pdf/rbcs/v31n1/18.pdf>. Acesso em: 15 de out. 2012. doi: <http://dx.doi.org/10.1590/ S0100-06832007000100018>.

NAKAGAWA, J. et al. Épocas de semeadura da soja. I. Efeitos na produção de grãos e nos componentes da produção. Pesquisa Agropecuária Brasileira, v.18, n.11, p.1187-1198, 1983.

NAKAGAWA, J. Testes de vigor baseados no desempenho de plântulas. In: KRZYZANOWSKI, F.C. Vigor de sementes. conceitos e testes. Londrina: ABRATES,1999. p.2-1/2-24.

NUNES, J.C. Tratamento de semente - qualidade e fatores que podem afetar a sua performance em laboratório. Londrina-PR: Syngenta Proteção de Cultivos, 2005. 16p.

PESKE, F.B. et al. Produtividade de plantas de soja provenientes de sementes tratadas com fósforo. Revista Brasileira de Sementes, v.31, n.1, p.95-101, 2009. Disponível em: <http://www.scielo.br/ pdf/rbs/v31n1/a11v31n1.pdf>. Acesso em: 15 de out. 2012. doi: <http://dx.doi.org/10.1590/S0101-31222009000100011>.

ROSSETTO, C.A.V. et al. Efeito da adubação potássica e da época de colheita na qualidade fisiológica de sementes de canola 
(Brassica napus L. var. oleifera Metzg.). Revista Brasileira de Sementes, v.19, n.2, p.348-353, 1997.

SOUZA, F.S. et al. Desenvolvimento radicular do algodoeiro em resposta à localização do fertilizante. Revista Brasileira de Ciência do Solo, v.31, n.2 p.387-392, 2007. Disponível em: $<$ http://www.scielo.br/pdf/rbcs/v31n2/a21v31n2.pdf>. Acesso em: 10 de out. 2012. doi: <http://dx.doi.org/10.1590/S010006832007000200021>.
STRECK, E.V. et al. Solos do Rio Grande do Sul. 2.ed. rev. ampl. Porto Alegre: EMATER/RS - ASCAR, 2008. 22p.

TAIZ, L.; ZEIGER, E. Fisiologia vegetal. 3.ed. Porto Alegre: Artmed, 2004. 719p.

VIEIRA, R.D. et al. Avaliação do efeito de doses de P e K na qualidade de sementes de soja. Revista Brasileira de Sementes, v.9, n.1, p.83-89, 1987. 